\title{
Application of Adaptive Neuro-Fuzzy Inference System for Evaluating Compressive Strength of Concrete
}

Deepak Kumar Sinha, Rupali Satavalekar, and Senthil Kasilingam

Department of Civil Engineering, Dr. B R Ambedkar National Institute of Technology, Jalandhar, India

\section{]jfis}

Received: Jan. 14, 2021

Revised : Mar. 30, 2021

Accepted: Apr. 26, 2021

Correspondence to: Rupali Satavalekar (satavalekarr@nitj.com)

(CThe Korean Institute of Intelligent Systems

cCThis is an Open Access article distributed under the terms of the Creative Commons Attribution Non-Commercial License (http://creativecommons.org/licenses/by-nc / 3.0/) which permits unrestricted noncommercial use, distribution, and reproduction in any medium, provided the original work is properly cited.

\begin{abstract}
The objectives of this study are to develop a model for predicting the compressive strength of concrete using an adaptive neuro-fuzzy inference system (ANFIS) and validate the mix proportion using artificial neural networks (ANNs) and by experimentation. A model was developed, and the compressive strength was predicted using the ANFIS (with the subtractive clustering method of the fuzzy inference system) by MATLAB programming. In the present study, two ANFIS models were considered: ANFIS models-1 and -2. ANFIS model-1 was developed to predict the 3-day compressive strength, whereas ANFIS model-2 predicts the 28-day compressive strength by considering the 3-day compressive strength data obtained using ANFIS model-1. It was observed that the errors in the 3- and 28-day compressive strengths were $6.33 \%$, and $17.07 \%$, respectively. Furthermore, experiments were performed for selective mixes-M40, M50, and M60 - to verify the compressive strength obtained using the ANFIS model. The model results were verified against the experimental ones based on the mixes selected from the model, and the results were found to agree with the predicted ones, with a maximum deviation of $18 \%$. Furthermore, an ANN model was developed to predict the compressive strength to verify the accuracy of the ANFIS model. The results predicted by the ANFIS and the ANN were compared with the original results available in the literature. A significant deviation was found between the ANN model results and the original results, however, the ANN model results presented the same trend as the original results. It was concluded that the ANFIS model results were highly consistent with the original results.
\end{abstract}

Keywords: Compressive strength of concrete, ANFIS, ANN, Subtractive clustering method, Experimental studies

\section{Introduction}

Concrete is the most commonly used material owing to its strength, durability, flexibility, and economy. It is extensively used in structural applications, such as buildings, bridges, roads, dams, pipes, kerbs, and drains. The various benefits of concrete ensure its easy casting. The design of a structure is based on the 28-day compressive strength because it is considered as the design strength. Although concrete production is easy, the mix design is a complex process requiring laborious calculations and experiments. Concrete mix design is the process of setting the proportions of the various constituents of concrete to achieve a set design strength as well as other desired properties. It is mostly an empirical procedure based on certain design codes. Generally, for mix design, certain tests are conducted, and cubes are casted and tested for 
strength at the end of 28 days. The curing time of 28 days is long, and in case of any failures, there is a further wait period of 28 days. Hence, it is important to develop a numerical or analytical model for reducing the curing time and predict the 28-day strength using the 3-day strength. By reducing the curing time, many indirect costs in construction activities can be reduced.

\subsection{Advances in Concrete Technology}

Kabir et al. [1] presented a simple mathematical model for predicting the compressive strength of concrete from its 7-day strength. The model uses a rational polynomial-based equation for relating various parameters with the age and strength of concrete. This model is found to produce satisfactory results for brick aggregates. Such mathematical models require expert knowledge of concrete strength interaction and adjustment of the parameters by trials and field expertise; making strength determination a complex process. Supe and Gupta [2] conducted a study to build a predictive model for in situ calculation of the compressive strength of concrete; specifically, they performed rapid curing at $100^{\circ} \mathrm{C}$ to predict the 1-day compressive strength and subsequently used it to predict the 28-day strength. Although this method is very easy to apply on-site even by a less experienced worker, its accuracy is not always acceptable. Viviani et al. [3] used a maturity method for predicting the compressive strength of concrete. They conducted early-age deformation monitoring of concrete samples using extensometers, which are optical fiber-based deformation sensors, to calculate equivalency points. These were subsequently used to compute the activation energy and maturity of concrete at 12 hours, which was further calibrated at 3 and 7 days. The activation energy was further used to determine the compressive strength of concrete. It was revealed that 72 hours are sufficient for collecting data and conducting the strength evaluation of concrete up to a desirable accuracy, instead of waiting for 28 days. Although this method has potential it involves sophisticated sensors and expert knowledge of the concrete age and interaction equations. To use such forecasting in the field, a procedure or a tool is required to reduce the application complexity for the construction industry.

\subsection{Artificial Intelligence in Concrete Technology}

Artificial intelligence (AI) or machine learning refers to any system that presents features associated with a human mind, such as learning and problem-solving. AI mimics human in- telligence and is used in expert, knowledge-based, and robot systems. In civil engineering problems such as engineering design, geotechnical engineering, construction planning, and scheduling, machine learning has been found to perform satisfactorily. In a detailed review, Akram et al. [4] also highlighted the advantages of expert systems. They concluded that an expert system is a useful tool for enabling practitioners in rapid decision-making. Abraham [5] concluded that AI is a broad field and comprises various approaches and methods. Chopra et al. [6] investigated the appropriate neural network (NN) architecture for predicting the compressive strength of concrete and compared it with a genetic learning (GL) model. It was concluded that the Aram NN outperformed the GL model.

Chen [7] stated that fuzzy logic-based AI produces a set of if-else rules for a given function. Its inputs and outputs are assigned membership functions, which are subsequently connected by an if-else rule set. Such a method is ideal for expert systems in which the input parameters are few, such as temperature controllers in an air conditioner [8]. The only problem is that a fuzzy-based system lacks learning capability. The adaptive neuro-fuzzy inference system (ANFIS) combines fuzzy logic with artificial neural network (ANN). The ANFIS, which was proposed by Jang [9], is a new fuzzy inference system (FIS) structure that combines fuzzy logic and an NN. Its hybrid algorithm is a combination of backpropagation algorithm and the least-squares method and is used to adjust the parameters and output of the FIS. The parameters can automatically generate the if-then rules. Nataraja et al. [10] presented a fuzzy-neuro model for the mix design of concrete based on IS 10262 [11]. They combined a five-layered-FIS with a trained three-layered $\mathrm{ANN}$, and for a required compressive strength of concrete, determined the composition of cement, fine aggregates (FAs), coarse aggregates (CAs), and water. It was concluded that the model works satisfactorily compared with conventional methods; however, the model produces slightly lower contents than the conventional method within an acceptable range.

\subsection{ANFIS Modeling in Concrete Technology}

Neshat et al. [12] used an ANFIS model and a fuzzy expert system (FES) model to develop a concrete mix design. They concluded that the ANFIS model performs equally well or even superior to the FES model, even though it requires much less effort or subject expertise than that needed in the FES model, in which the if-else rules have to be manually input into the system by an expert. Ghoddousi et al. [13] presented a set of FES 
and ANFIS submodels for the mix design of concrete. It was concluded that the model successfully provides the quantities of the various components for the mix design, ensuring maximum packing density and minimum cement content for a given design strength. Sinha et al. [14] developed an ANFIS-based model for predicting the compressive strength of high-performance concrete (HPC). The model incorporates seven input variables and one output variable. Subtractive clustering was used as the base FIS and hybrid algorithm for training. With an optimum set of FIS parameters, the model was found to accurately predict the compressive strength, thus making the ANFIS suitable even for concrete with numerous ingredients, as in the case of HPC, for which other models lack accuracy and simplicity. In addition, the ANFIS has been used for many other problems in the field of civil engineering, including mechanical properties [15 16], ductility factor [17], and strain in concrete beams [18[19].

\subsection{Observation and Objectives of Present Study}

Based on a detailed literature review, it was found that AI methodologies have been commonly applied in the field of concrete technology. However, prediction of the compressive strengths of different ages of concrete using the ANFIS model was found to be limited. In addition, only few advantages were found for the prediction of compressive strength using ANFIS and ANN methods. Thus far, experiments on mixes proposed by a trained model has not been conducted. The novelty of the present study is the development of an ANFIS model for the prediction of the compressive strengths of concretes of different ages, which will lead to time-saving for decision-making. The application of an expert system, such as the ANFIS model, in the field of concrete technology is another novelty of this study. Specifically, the present study was focused on developing a model for predicting the compressive strength of concrete and to verify its accuracy by experimentation at different stages ( 3 and 28 days). The ANFIS model was developed using MATLAB [20] software, and it considered three inputs to predict the cement comment, water/cement ratio, and 28-day compressive strength from the 3-day compressive strength of concrete, as discussed in Section 2. Furthermore, the model was developed to predict the compressive strength using an ANN (refer Section $3)$. The experimentation was conducted for selective mixes, and the results were compared with those of the ANFIS model results (see Section 4). Further, the results predicted using the ANFIS and the ANN were compared to the original results by Yeh [21], as discussed in Section 5.

\section{Prediction of Compressive Strength using AN- FIS Model}

\subsection{Application of ANFIS Model to Concrete}

There are numerous applications of the ANFIS in the fields of concrete technology and structural engineering. The ANFIS has been used to model concrete strength in numerous studies [12-14]. In addition, the ANFIS is used for the prediction of concrete compressive strength based on various nondestructive tests [15-17]. Therefore, the techniques proposed in this paper are feasible and viable for application to the ANFIS model in the measurement of concrete strength.

The ANFIS is a new FIS structure that combines fuzzy logic and NNs [9]. The shortcomings of ANNs and fuzzy logic are addressed by the ANFIS. The backpropagation algorithm and the least squares method are combined used to adjust the parameters and outputs. The ANFIS uses fuzzy NNs to realize fuzzy control, fuzzy reasoning, and anti-fuzzification. The rules are extracted from the sample data to form an adaptive neural fuzzy controller. Offline and online learning algorithms are used to adjust the fuzzy inference control rules, allowing the system to become adaptive, self-organizing, and self-learning. The ANFIS model architecture is shown in Figure 1. The ANFIS is a five-layered network comprising the following: fuzzifying layer, ruleset layer, normalizing layer, de-fuzzifying layer, and single summation neuron. The ANFIS uses the learning ability of the ANNs to identify patterns and develops an FES based on training in the form of an FIS file, which helps in understanding the patterns in the data. Thus, it is a suitable method excluding the shortcomings of the most used ANNs and fuzzy logic.

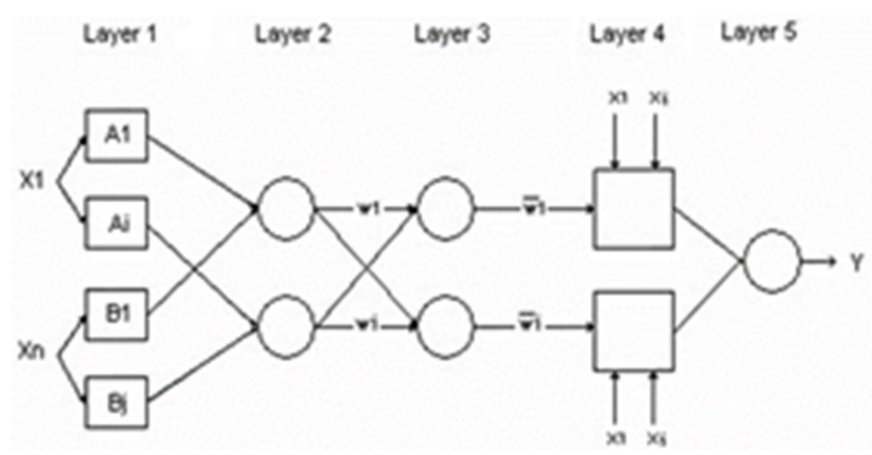

Figure 1. Architecture of ANFIS [7]. 
Table 1. Dataset used for modeling [21]

\begin{tabular}{cccccccccc}
\hline S. No. & $\begin{array}{c}\text { Cement } \\
\left(\mathrm{kg} / \mathrm{m}^{3}\right)\end{array}$ & $\begin{array}{c}\text { BFS } \\
\left(\mathrm{kg} / \mathrm{m}^{3}\right)\end{array}$ & $\begin{array}{c}\text { Fly ash } \\
\left(\mathrm{kg} / \mathrm{m}^{3}\right)\end{array}$ & $\begin{array}{c}\text { Water } \\
\left(\mathrm{kg} / \mathrm{m}^{3}\right)\end{array}$ & $\begin{array}{c}\text { Superplasticizer } \\
\left(\mathrm{kg} / \mathrm{m}^{3}\right)\end{array}$ & $\begin{array}{c}\mathrm{CA} \\
\left(\mathrm{kg} / \mathrm{m}^{3}\right)\end{array}$ & $\begin{array}{c}\text { FA } \\
\left(\mathrm{kg} / \mathrm{m}^{3}\right)\end{array}$ & $\begin{array}{c}\text { Age } \\
(\text { day })\end{array}$ & $\begin{array}{c}\text { Compressive } \\
\text { strength } \\
(\mathrm{MPa})\end{array}$ \\
\hline 1 & 540.0 & 0 & 0 & 162.0 & 2.5 & 1040.0 & 676.0 & 28 & 79.99 \\
2 & 540.0 & 0 & 0 & 162.0 & 2.5 & 1055.0 & 676.0 & 28 & 61.89 \\
\hline 3 & 332.5 & 142.5 & 0 & 228.0 & 0 & 932.0 & 594.0 & 270 & 40.27 \\
\hline 4 & 332.5 & 142.5 & 0 & 228.0 & 0 & 932.0 & 594.0 & 365 & 41.05 \\
\hline 5 & 198.6 & 132.4 & 0 & 192.0 & 0 & 978.4 & 825.5 & 360 & 44.30 \\
\hline 6 & 266.0 & 114.0 & 0 & 228.0 & 0 & 932.0 & 670.0 & 90 & 47.03 \\
\hline 7 & 380.0 & 95.0 & 0 & 228.0 & 0 & 932.0 & 594.0 & 365 & 43.70 \\
\hline 8 & 380.0 & 95.0 & 0 & 228.0 & 0 & 932.0 & 594.0 & 28 & 36.45 \\
\hline 9 & 266.0 & 114.0 & 0 & 228.0 & 0 & 932.0 & 670.0 & 28 & 45.85 \\
10 & 475.0 & 0 & 0 & 228.0 & 0 & 932.0 & 594.0 & 28 & 39.29 \\
11 & 198.6 & 132.4 & 0 & 192.0 & 0 & 978.4 & 825.5 & 90 & 38.07 \\
12 & 198.6 & 132.4 & 0 & 192.0 & 0 & 978.4 & 825.5 & 28 & 28.02 \\
\hline 1,030 & 260.9 & 100.5 & 78.3 & 200.6 & 8.6 & 864.5 & 761.5 & 28 & 32.40 \\
\hline
\end{tabular}

\subsection{ANFIS Models-1 and 2}

In the present study, two models were considered: ANFIS models-1 and 2. ANFIS model-1 comprises seven inputs and one output. The seven inputs are cement, blast furnace slag (BFS), fly ash, water, superplasticizer, CAs, and FAs, whereas the output is the 3-day compressive strength. ANFIS model-2 comprises three inputs and one output. The three inputs are cement, water, and the 3-day compressive strength, whereas the output is the 28-day compressive strength. ANFIS modeling was performed on MATLAB [20] using the Neuro-fuzzy designer package. The datasets used were divided into three sets: $80 \%$ of the parameters were for training, $10 \%$ for checking, and $10 \%$ for validation. The modeling included training the data, checking the data, generating the FIS, and training and testing of the FIS with the validation set. In general, the FIS is generated by two methods: grid partition and subtractive clustering methods. The grid partition method results in a paralyzed computational system, whereas the subtractive clustering method is a rule-based model that can be achieved with comparatively lesser computing power. In the present study, subtractive clustering was used to optimize four parameters: range of influence, squash factor, accept ratio, and reject ratio. The range of influence determines the radius of the clusters; a large number of cluster points implies high accuracy of the model; however, it is recommended to keep the number of cluster points small.

\subsection{Datasets}

A dataset of concrete mix proportions adopted by Yeh [21] was used to conduct the present study. The dataset contains 1,030 samples including nine parameters: cement, BFS, fly ash, water, superplasticizer, CAs, FAs, age, and compressive strength, and a few samples are listed in Table 1. To predict the 28-day compressive strength from the 3-day compressive strength, a dataset that contains the concrete parameters with both 3- and 28-day compressive strengths is required. However, there is no such dataset available in the literature, and because of which a new dataset was created using ANFIS modeling. The dataset summarized in Table 1 is split into two datasets: one containing 3-day compressive strength and the other 28-day compressive strength (Tables 2 and 3).

\subsection{Optimizing Data}

Data optimization is a process of improving data integrity by restructuring existing relational data. In the present investigation, four methods were explored for data optimization to identify the best optimization technique. The first method, was to use the data in the original form, and this approach was found to be unsuitable. In the second one, the data of compressive strengths were arranged in ascending order; however, this was inappropriate for the analysis. In the third method, data with variables in normalized forms were considered, and this approach also 
Table 2. Range of variables and 3-day compressive strength used in dataset-1 [21]

\begin{tabular}{ccccccccc}
\hline Range & $\begin{array}{c}\text { Cement } \\
\left(\mathrm{kg} / \mathrm{m}^{3}\right)\end{array}$ & $\begin{array}{c}\text { BFS } \\
\left(\mathrm{kg} / \mathrm{m}^{3}\right)\end{array}$ & $\begin{array}{c}\text { Fly ash } \\
\left(\mathrm{kg} / \mathrm{m}^{3}\right)\end{array}$ & $\begin{array}{c}\text { Water } \\
\left(\mathrm{kg} / \mathrm{m}^{3}\right)\end{array}$ & $\begin{array}{c}\text { Super- } \\
\text { plasticizer } \\
\left(\mathrm{kg} / \mathrm{m}^{3}\right)\end{array}$ & $\begin{array}{c}\mathrm{CA} \\
\left(\mathrm{kg} / \mathrm{m}^{3}\right)\end{array}$ & $\begin{array}{c}\mathrm{FA} \\
\left(\mathrm{kg} / \mathrm{m}^{3}\right)\end{array}$ & $\begin{array}{c}\text { 3-day } \\
\text { compressive } \\
\text { strength }(\mathrm{MPa})\end{array}$ \\
\hline Min & 102 & 0 & 0 & 121.75 & 0 & 822 & 605 & 2.3 \\
Max & 540 & 305.3 & 174.74 & 214.6 & 32.2 & 1134.5 & 992.6 & 41.6 \\
\hline
\end{tabular}

Table 3. Range of variables and 28-day compressive strength used in dataset 2 [21]

\begin{tabular}{ccccccccc}
\hline Range & $\begin{array}{c}\text { Cement } \\
\left(\mathrm{kg} / \mathrm{m}^{3}\right)\end{array}$ & $\begin{array}{c}\text { BFS } \\
\left(\mathrm{kg} / \mathrm{m}^{3}\right)\end{array}$ & $\begin{array}{c}\text { Fly ash } \\
\left(\mathrm{kg} / \mathrm{m}^{3}\right)\end{array}$ & $\begin{array}{c}\text { Water } \\
\left(\mathrm{kg} / \mathrm{m}^{3}\right)\end{array}$ & $\begin{array}{c}\text { Super- } \\
\text { plasticizer } \\
\left(\mathrm{kg} / \mathrm{m}^{3}\right)\end{array}$ & $\begin{array}{c}\mathrm{CA} \\
\left(\mathrm{kg} / \mathrm{m}^{3}\right)\end{array}$ & $\begin{array}{c}\mathrm{FA} \\
\left(\mathrm{kg} / \mathrm{m}^{3}\right)\end{array}$ & $\begin{array}{c}\text { 28-day } \\
\text { compressive } \\
\text { strength }(\mathrm{MPa})\end{array}$ \\
\hline Min & 102 & 0 & 0 & 121.75 & 0 & 801 & 594 & 8.5 \\
Max & 540 & 359.4 & 200.1 & 247 & 32.2 & 1145 & 992.6 & 81.8 \\
\hline
\end{tabular}

Table 4. Results of trials for dataset optimization

\begin{tabular}{cccc}
\hline S. No & Type of data & Training error (RMSE) & Testing error (RMSE) \\
\hline 1 & Original data & 3.839 & 4.216 \\
2 & Increasing order data & 9.231 & 79.221 \\
3 & Normalized data & 2.8 & 4.492 \\
4 & Variables expressed as ratio of cement & 2.53 & 3.2 \\
\hline
\end{tabular}

was found unsuitable. In the fourth method, data with variables expressed as ratios of the first variable (i.e., cement) were used, and it was found to be appropriate for performing the analysis. Therefore, the fourth method was adopted to optimize the data. The results of these trials were obtained in terms of the root mean square errors (RMSEs) (Table 4). It can be seen that the smallest error is obtained when the data are expressed as the ratio of the first variable (i.e., cement) hence, for the model development, the variables were expressed as the ratio of cement. The converted values of the various parameters as ratios of cement are listed in Table 5, which were subsequently used for the model generation.

\subsection{Flowchart and Modeling Process}

The modeling approach adopted in this study is shown as a flowchart in Figure 2. Two ANFIS models-ANFIS models1 and -2-were developed. It should be noted that ANFIS model-2 is the key to predicting the mix proportions and 28-day compressive strengths of the concrete mixes. The latter were obtained using ANFIS model-1, which yields 3-day strengths for the dataset, which were subsequently used to develop ANFIS model-2. Based on the flowchart, after formulating and optimizing ANFIS model-1 using the dataset, the 3-day compressive strength is measured from an experiment. In comparison, ANFIS model-2 is developed based on the output from ANFIS model-1.

ANFIS model-1 produces the 3-day compressive strength, whereas ANFIS model-2 yields the 28-day compressive strength from the existing 3-day compressive strength. Dataset-1 is used for learning ANFIS model-1. Normalized input parameters, such as cement, BFS, fly ash, water, superplasticizer, CAs, and FAs, are considered in ANFIS model-1, as shown in Figure 3. The dataset is divided into three parts-training $(80 \%)$, checking (10\%), and validation (10\%), the subtractive clustering parameters derived from the orthogonal array testing for this model are (i) range of influence $=0.05$, (ii) squash factor $=1.25$, (iii) acceptability ratio $=0.5$, and (iv) reject ratio $=0.15$. ANFIS model- 1 has the following properties: number of nodes $=1,610$; number of linear parameters $=800$; number of nonlinear parameters $=1,400$; total number of parameters $=2,200$; number of training data pairs $=107$; number of checking data pairs $=14$; and number of fuzzy rules $=100$.

The structure of ANFIS model-1, which possesses a fivelayered network, is shown in Figure 4. The model was trained using the training and checking subsets of dataset-1. As shown in Figure 5, the RMSE achieved for the training dataset is 0.15 $\mathrm{MPa}$ and for the checking dataset is $5.15 \mathrm{MPa}$. The results were 
Table 5. Inputs converted into ratios of first variable (cement)

\begin{tabular}{|c|c|c|c|c|c|c|c|}
\hline $\begin{array}{l}\text { Cement } \\
\left(\mathrm{kg} / \mathrm{m}^{3}\right)\end{array}$ & $\begin{array}{c}\text { BFS/ } \\
\text { cement }\end{array}$ & $\begin{array}{l}\text { Fly ash/ } \\
\text { cemnet }\end{array}$ & $\begin{array}{c}\text { Water/ } \\
\text { cement }\end{array}$ & $\begin{array}{c}\text { Super- } \\
\text { plasticizer/ } \\
\text { cement }\end{array}$ & $\mathrm{CA} /$ cement & FA/cement & $\begin{array}{c}\text { 3-day } \\
\text { compressive } \\
\text { strength }\end{array}$ \\
\hline 139.60 & 1.50 & 0 & 1.375358166 & 0 & 7.5 & 5.78008596 & 8.06342182 \\
\hline 349.00 & 0.00 & 0 & 0.550143266 & 0 & 3 & 2.31203484 & 15.04919265 \\
\hline 198.60 & 0.67 & 0 & 0.966767372 & 0 & 4.926485398 & 4.156596173 & 9.131420144 \\
\hline 310.00 & 0.00 & 0 & 0.619354839 & 0 & 3.132258065 & 2.743870968 & 9.86640156 \\
\hline 374.00 & 0.51 & 0 & 0.454812834 & 0.027005348 & 2.476203209 & 2.023262032 & 34.39795764 \\
\hline 313.30 & 0.84 & 0 & 0.560165975 & 0.027449729 & 3.341525694 & 1.952760932 & 28.79941252 \\
\hline 425.00 & 0.25 & 0 & 0.361176471 & 0.038823529 & 2.004941176 & 2.087294118 & 33.39821744 \\
\hline 425.00 & 0.25 & 0 & 0.356235294 & 0.043764706 & 2.202352941 & 1.891058824 & 36.3009114 \\
\hline 375.00 & 025 & 0 & 0.3376 & 0.0624 & 2.272266667 & 2.646933333 & 28.99936056 \\
\hline 475.00 & 0.25 & 0 & 0.0381263158 & 0.018736842 & 1.793894737 & 1.645263158 & 37.79707432 \\
\hline 469.00 & 0.25 & 0 & 0.293816631 & 0.068656716 & 1.81684435 & 1.792110874 & 40.1964508 \\
\hline 425.00 & 0.25 & 0 & 0.0361176471 & 0.038823529 & 2.004941176 & 2.087294118 & 33.39821744 \\
\hline 388.60 & 0.25 & 0 & 0.406330417 & 0.031137416 & 2.192743181 & 2.382141019 & 28.096147 \\
\hline 531.30 & 0.00 & 0 & 0.266892528 & 0.053077357 & 1.603801995 & 1.682100508 & 41.2996124 \\
\hline 425.00 & 0.25 & 0 & 0.361176471 & 0.038823529 & 2.004941176 & 2.087294118 & 33.39821744 \\
\hline 318.80 & 0.67 & 0 & 0.488393977 & 0.044855709 & 2.672935634 & 2.761606023 & 25.2003478 \\
\hline 401.80 & 0.24 & 0 & 0.366849179 & 0.02837325 & 2.356396217 & 2.120706819 & 41.09966436 \\
\hline 362.60 & 0.52 & 0 & 0.454771098 & 0.031991175 & 2.605350248 & 2.084390513 & 35.3011712 \\
\hline 323.70 & 0.87 & 0 & 0.5678097 & 0.031819586 & 2.912264442 & 2.038616002 & 28.29609504 \\
\hline 379.50 & 0.40 & 0 & 0.405533597 & 0.041897233 & 2.988932806 & 1.594202899 & 28.59946448 \\
\hline
\end{tabular}

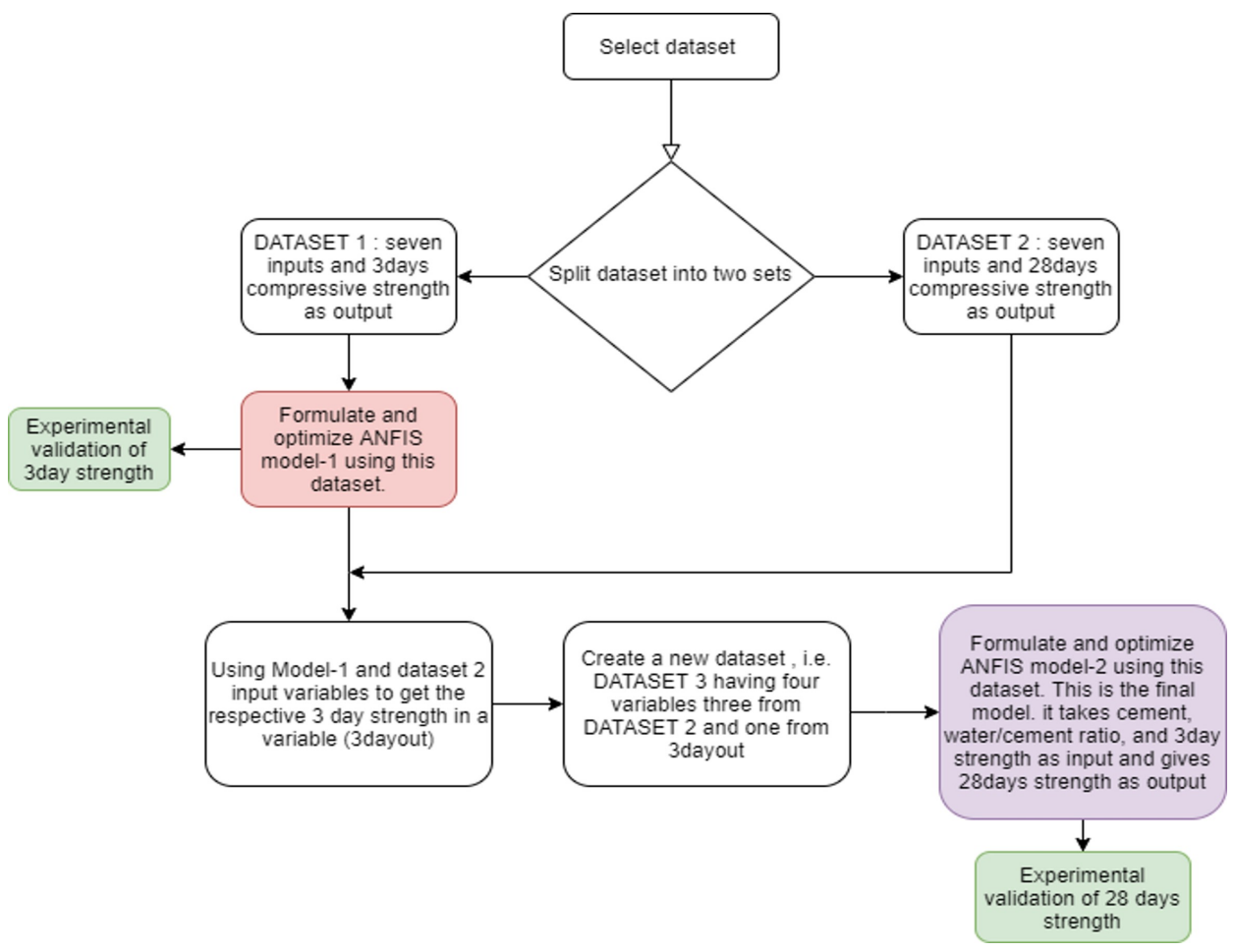

Figure 2. Flowchart of modeling process. 


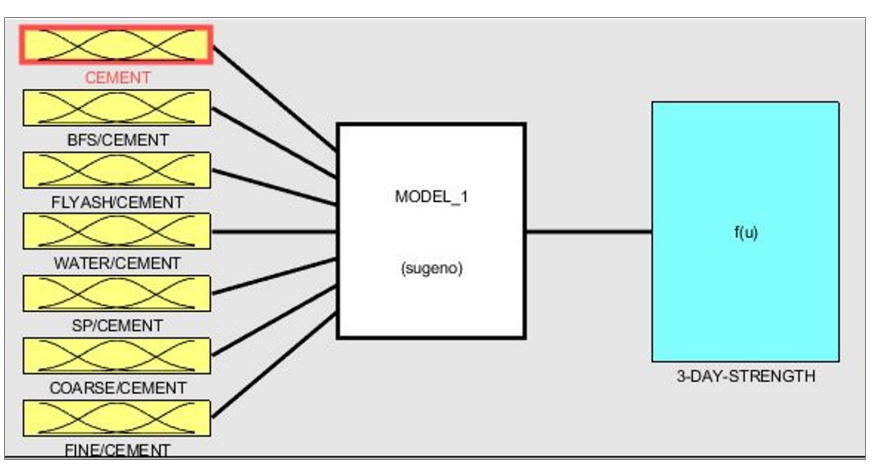

Figure 3. ANFIS model-1.

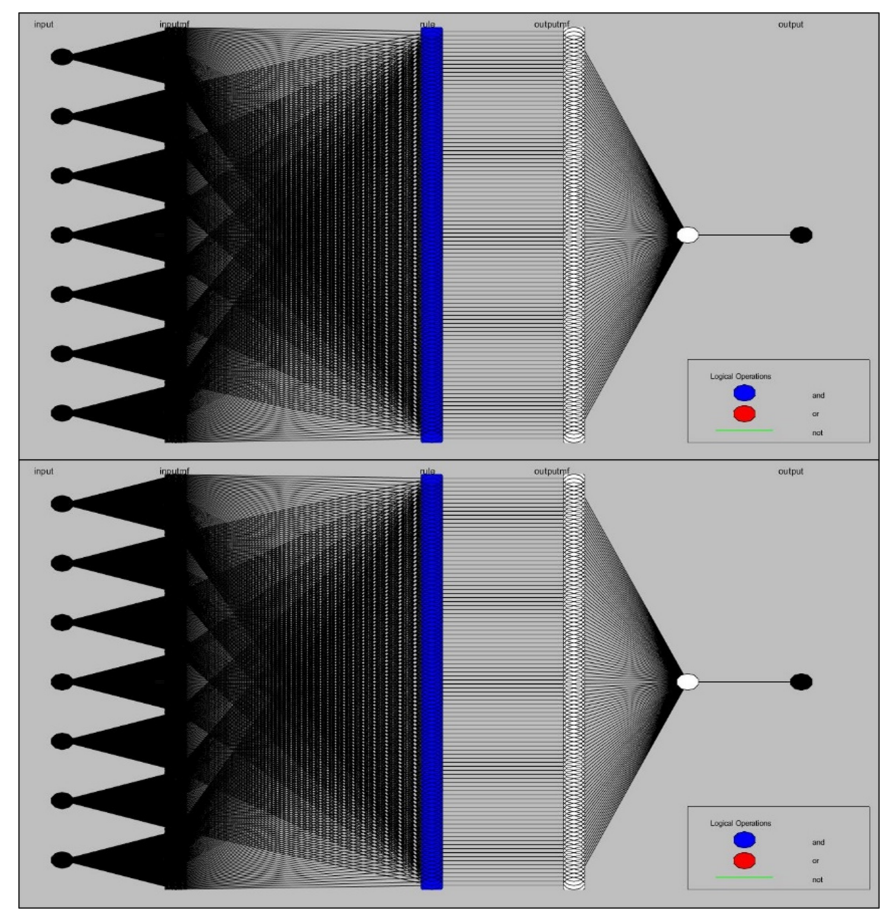

Figure 4. ANFIS model-1 structure.

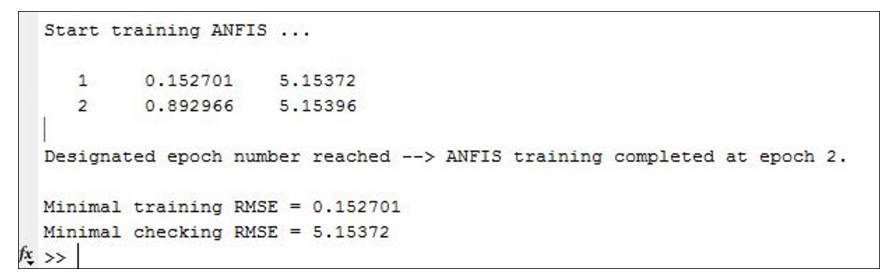

Figure 5. Training of ANFIS model-1.

further validated with the testing dataset, as shown in Figure 6. It can be that the obtained RMSE is $4.7 \mathrm{MPa}$, which is acceptable.

ANFIS model-1 is used to obtain the 3-day strength from dataset-2 (Table 3), which contains the 28-day strength. This approach is used to obtain a dataset containing both 3- and

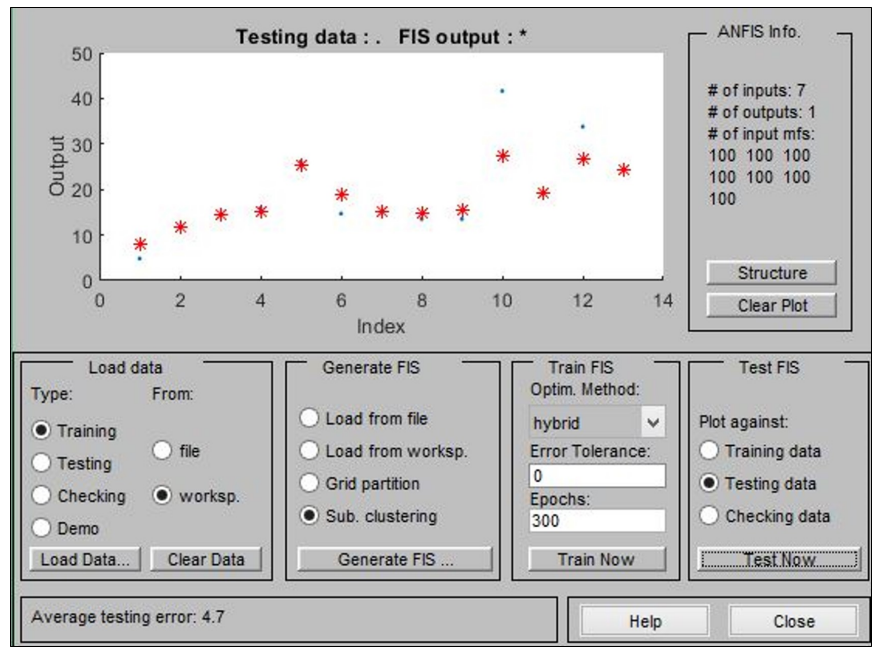

Figure 6. Validation of ANFIS model-1.

28-day strengths for the same input variables. This is achieved by exporting the FIS of model-1 into the workspace. Using the following command, the output is stored in a variable named 3dayout:

$$
\text { 3dayout }=\text { evalfis(input, } \text { model_1 }) .
$$

A new dataset, i.e., dataset- 3 is created based on the output variables as well as dataset-2. Dataset-3 has four variables: cement, water/cement, 3-day compressive strength, and 28-day compressive strength. Of these, cement, water/cement, and 28-day strength are taken from dataset-2, and the 3-day compressive strength from the model-1 output ( 3 dayout). ANFIS model-2 is developed using dataset-3 to determine the 28-day compressive strength (Table 6). ANFIS model-2 considers three input variables: cement, water/cement, and 3-day compressive strength, as presented in Figure 7. ANFIS model-2 uses dataset3 for training and validation. Dataset-3 is divided into three subsets: training, checking, and validating with $80 \%, 10 \%$, and $10 \%$ data, respectively. Subtractive clustering is optimized by altering four parameters: range of influence, squash factor, acceptance ratio, and reject ratio. It is observed that the range of influence determines the radius of clusters; a low value implies a large number of cluster points and high accuracy of the model.

The subtractive clustering parameters of ANFIS model-2 are range of influence 0.01 , squash factor 1.25 , acceptance ratio 0.5 , and rejection ratio 0.15 . The ANFIS model information and structure are presented in Figure 8, and the training and checking errors are shown in Figure 9. It can be seen that the RMSEs for the training and checking of model 2 are 1.11 and 6.5 , respectively. 
Table 6. Dataset-3 for ANFIS model-2

\begin{tabular}{ccccc}
\hline S. No. & Cement & $\begin{array}{c}\text { Water/ } \\
\text { cement }\end{array}$ & $\begin{array}{c}\text { 3-day } \\
\text { compressive } \\
\text { strength }\end{array}$ & $\begin{array}{c}\text { 28-day } \\
\text { compressive } \\
\text { strength }\end{array}$ \\
\hline 1 & 540 & 0.3 & 27.45 & 79.99 \\
\hline 2 & 540 & 0.3 & 27.45 & 61.89 \\
\hline 3 & 380 & 0.6 & 16.45 & 36.45 \\
\hline 4 & 266 & 0.9 & 9.80 & 45.85 \\
\hline 5 & 475 & 0.5 & 24.15 & 39.29 \\
\hline 6 & 198.6 & 1 & 8.66 & 28.02 \\
\hline 7 & 304 & 0.8 & 17.85 & 47.81 \\
\hline 8 & 139.6 & 1.4 & 8.06 & 28.24 \\
\hline 9 & 427.5 & 0.5 & 20.88 & 37.43 \\
\hline 10 & 237.5 & 1 & 15.80 & 30.08 \\
\hline 11 & 332.5 & 0.7 & 12.24 & 33.02 \\
\hline 12 & 190 & 1.2 & 5.06 & 40.86 \\
\hline 13 & 485 & 0.3 & 24.65 & 71.99 \\
\hline 14 & 374 & 0.5 & 34.39 & 61.09 \\
\hline 15 & 313.3 & 0.6 & 28.79 & 59.8 \\
\hline 16 & 425 & 0.4 & 33.39 & 60.29 \\
\hline 17 & 425 & 0.4 & 36.30 & 61.8 \\
\hline 18 & 375 & 0.3 & 28.99 & 56.7 \\
\hline 19 & 475 & 0.4 & 37.79 & 68.3 \\
\hline$\ldots$ & $\ldots$ & $\ldots$ & $\ldots$ & $\ldots$ \\
\hline 425 & 469 & 0.3 & 40.19 & 66.9 \\
\hline & & & & \\
\hline
\end{tabular}

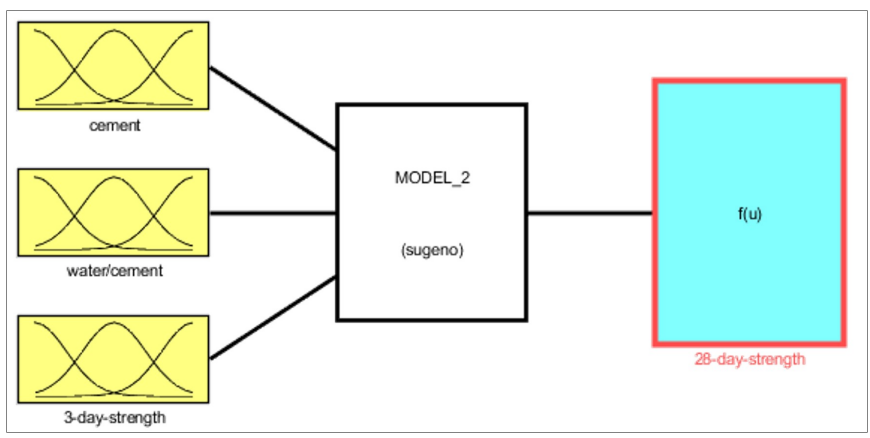

Figure 7. ANFIS model-2.

Figure 10 shows that an RMSE of $6.4696 \mathrm{MPa}$ is obtained for ANFIS model-2, which validates its accuracy. It is lower than the tolerance limit suggested in [22] for the computation of the target strength of concrete, which is given by

$$
f_{c m}=f_{c k}+1.65 \sigma
$$

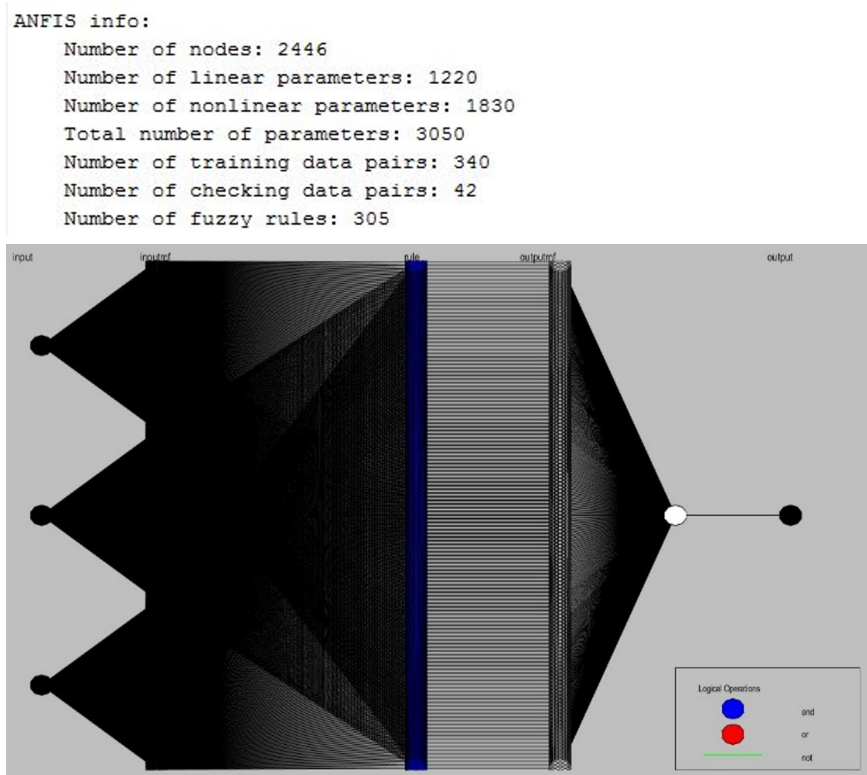

Figure 8. ANFIS model-2 structure.

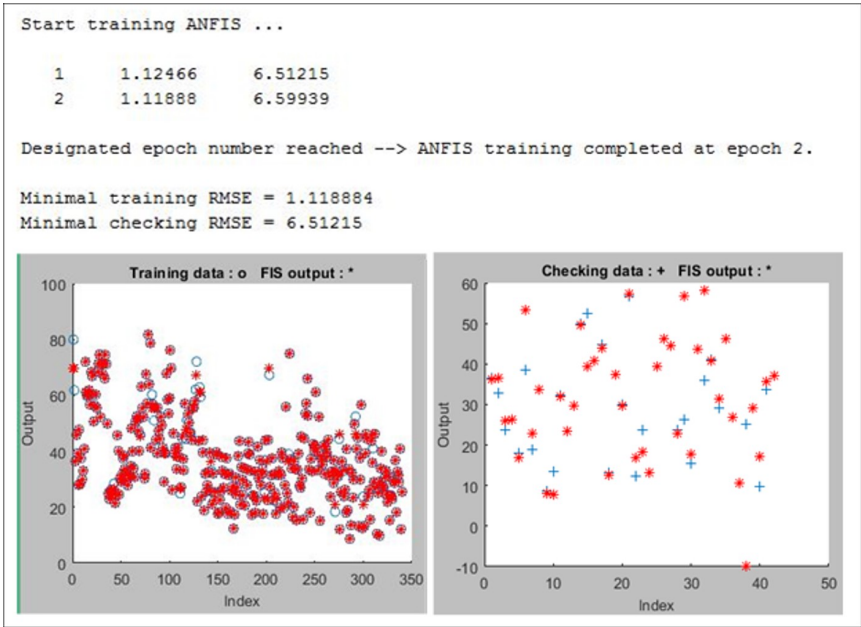

Figure 9. ANFIS model-2 training results.

where $f_{c m}$ is the mean target strength, $f_{c k}$ is the compressive strength, and $\sigma$ is the standard deviation. It was concluded that ANFIS model-2 was the key to predict the mix proportions and 28-day strengths of the concrete mixes. The latter were obtained using ANFIS model-1, which yields the 3-day strength for the dataset. The training, checking, and validation errors for ANFIS model-2 were $1.119,6.512$, and $6.469 \mathrm{MPa}$, respectively. These were within the tolerance limit of the mix design according to Indian codal recommendations. 


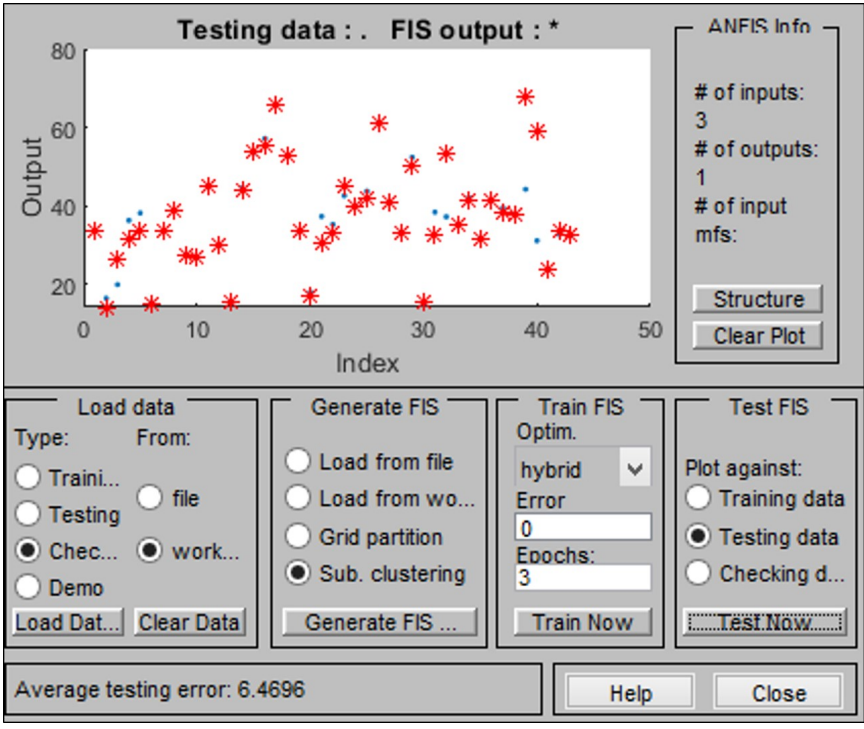

Figure 10. Validation of ANFIS model-2.

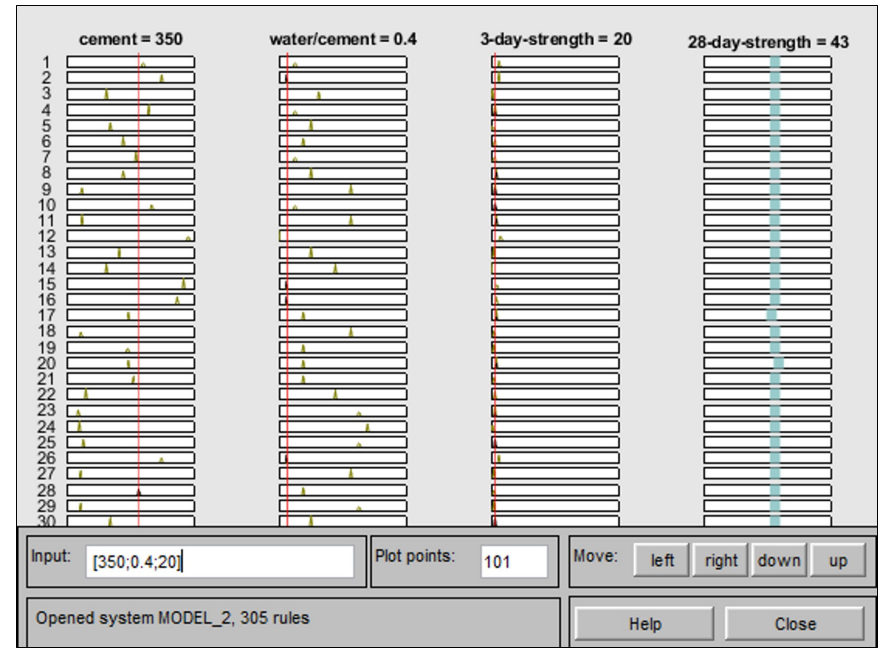

Figure 11. ANFIS model-2 rule viewer.

\subsection{ANFIS Ruleset}

ANFIS model-2 was used visually using the rule viewer window shown in Figure 11. These are standard if-else rules, which connect various variables with each other. This window allows a user to control the inputs graphically by sliders to achieve the respective outputs in real time. The inputs were entered in the command field at the bottom-left side of the window.

\subsection{ANFIS Surface Diagrams}

The surface diagram functions of "cement and water/cement ratio," "cement and 3-day strength," and "water/cement ratio and 3-day strength" were predicted using ANFIS model-2, as shown in Figures 12(a)-(c). These diagrams present the relationships of various variables with each other as well as with the compressive strength. Figure 12(a) shows the compressive strength relationship with cement and water/cement ratio, and it is observed that with increasing water/cement ratio, the strength decreases sharply. In addition, increasing the cement does not contribute to the compressive strength, as there is very little water. Figure 12(b) shows the relationship between cement and the 3-day strength, and with a high cement content and a high 3-day strength, the 28-day strength is high. Figure 12(c) presents the relationship between the water/cement ratio and the 3-day strength, and the strength decreases with increasing water/cement ratio.

\section{Prediction of Compressive Strength using ANN Model}

The ANN model was developed using MATLAB [20] to predict the compressive strength of concrete. The ANN model considered the normalized values of cement, BFS, fly ash, water, superplasticizer, CAs, and FAs as the seven inputs, similar to the ANFIS model illustrated in Figure 13. The considered dataset was divided into three parts: training (70\%), checking $(15 \%)$, and validation (15\%). The ANN model aims to generate a relation in the form of

$$
y^{m}=f\left(x^{n}\right),
$$

where $x^{n}$ is an $n$-dimensional input vector consisting of variables $x_{1}, \ldots, x_{i}, \ldots, x_{n}$, and $y_{m}$ is an m-dimensional output vector consisting of variables $y_{1}, \ldots, y_{i}, \ldots, y_{m}$ [23|24].

The training function, TrainLM, was used; the performance function was the mean squared error (MSE); the number of neurons was 10 , and the transfer function considered for the first and second layers was TANSIG, which is a tan-sigmoid transfer function. The transfer function calculates the output of the layer from the net input. The Levenberg-Marquardt (LM) optimization is the most commonly used algorithm and locates the minimum sum of squares of nonlinear functions. LM optimization is a combination of the steepest descent and the Gauss-Newton method. It assumes the steepest descent form for ensuring convergence when the solution is away from the correct value, whereas it assumes the Gauss-Newton method [25] when the solution is close to the correct one. The overall $R^{2}$ achieved is $95.3 \%$ (0.95305), as illustrated in Figure 14 . 


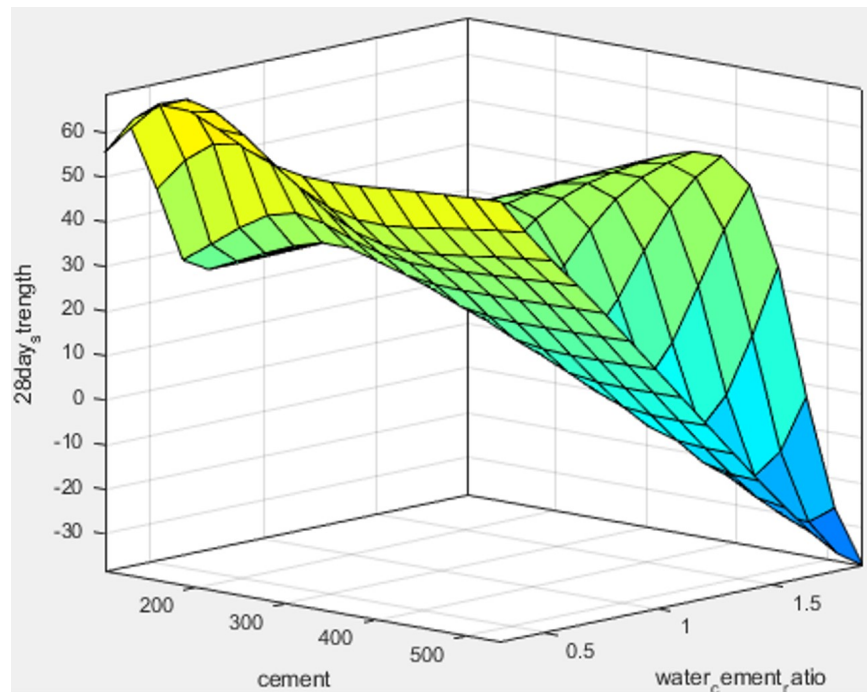

(a)

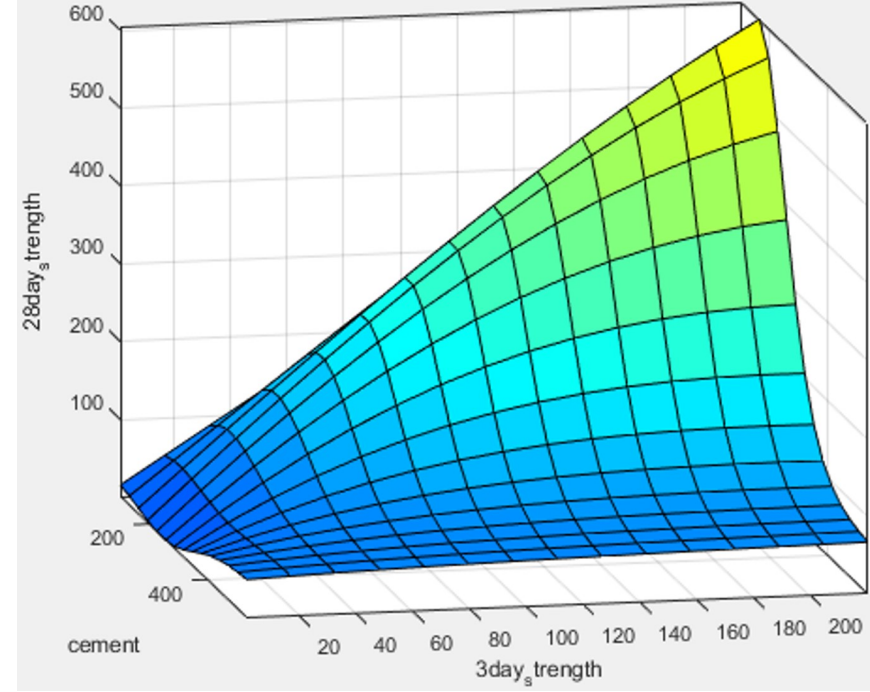

(b)

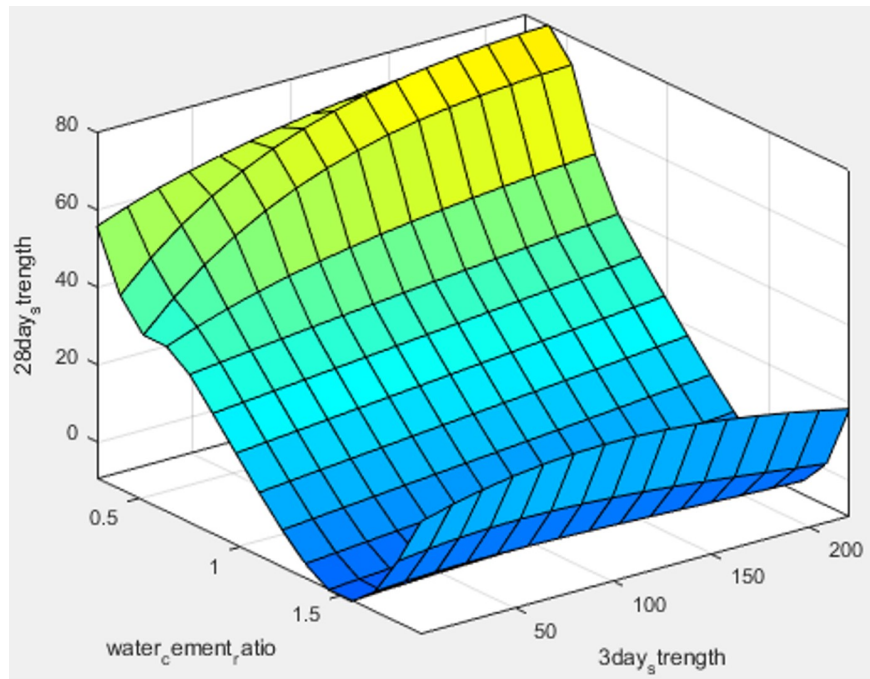

(c)

Figure 12. Surface diagrams for 28-day strength function of (a) cement and water/cement ratio, (b) cement and 3-day strength, and (c) water/cement ratio and 3-day strength.

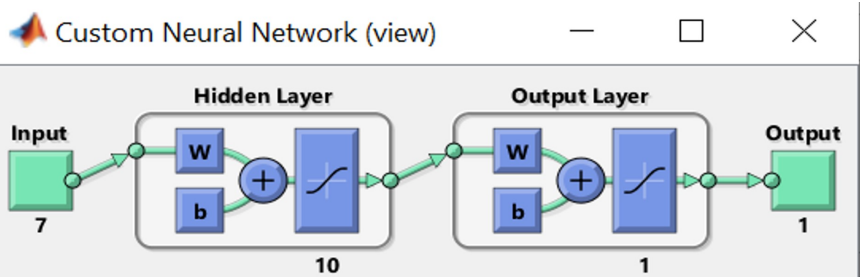

Figure 13. ANN model structure.

\section{Comparison of ANFIS Results and Experi- ment}

The 3- and 28-day compressive strengths obtained using the ANFIS model were validated using experimental results. The proportions of three mixes (M40, M50, and M60) were generated using the rule viewer from ANFIS model-1 for the 3-day strength and from ANFIS model-2 for the 28-day strength. Cylinders with $15-\mathrm{cm}$ diameter and $30-\mathrm{cm}$ depth were cast based on the mix proportions of the materials obtained from the ANFIS model. The materials considered in the present study and the 3- and 28-day concrete cylindrical compressive strengths are summarized in Table 7.

It can be seen from Table 7 that the average percentage of error for the 3-day compressive strength is $6.33 \%$, whereas for the 28-day compressive strength is $17.07 \%$. The calculated error for the 3-day compressive strength is much lower than that for 
Table 7. Comparison of ANFIS and experimental results

\begin{tabular}{|c|c|c|c|c|c|c|c|c|c|c|}
\hline \multirow{3}{*}{ Mix } & \multirow{3}{*}{$\begin{array}{l}\text { Cement } \\
\left(\mathrm{kg} / \mathrm{m}^{3}\right)\end{array}$} & \multirow{3}{*}{$\begin{array}{c}\text { FA } \\
\left(\mathrm{kg} / \mathrm{m}^{3}\right)\end{array}$} & \multirow{3}{*}{$\begin{array}{c}\mathrm{CA} \\
\left(\mathrm{kg} / \mathrm{m}^{3}\right)\end{array}$} & \multirow{3}{*}{$\begin{array}{c}\text { Water/cement } \\
\text { ratio }\end{array}$} & \multicolumn{4}{|c|}{ Compressive strength (MPa) } & \multirow{2}{*}{\multicolumn{2}{|c|}{ Error $(\%)$}} \\
\hline & & & & & \multicolumn{2}{|c|}{ ANFIS model } & \multicolumn{2}{|c|}{ Experiment } & & \\
\hline & & & & & 3-day & 28-day & 3-day & 28-day & 3-day & 28-day \\
\hline M40 & 470 & 695 & 916 & 0.40 & 23.9 & 43.0 & 25.64 & 36.50 & 7.28 & 16.27 \\
\hline M50 & 531 & 756 & 1023 & 0.35 & 27.0 & 57.3 & 29.62 & 48.56 & 9.70 & 17.90 \\
\hline M60 & 500 & 712 & 963 & 0.30 & 25.4 & 67.6 & 24.89 & 57.75 & 2.00 & 17.06 \\
\hline
\end{tabular}
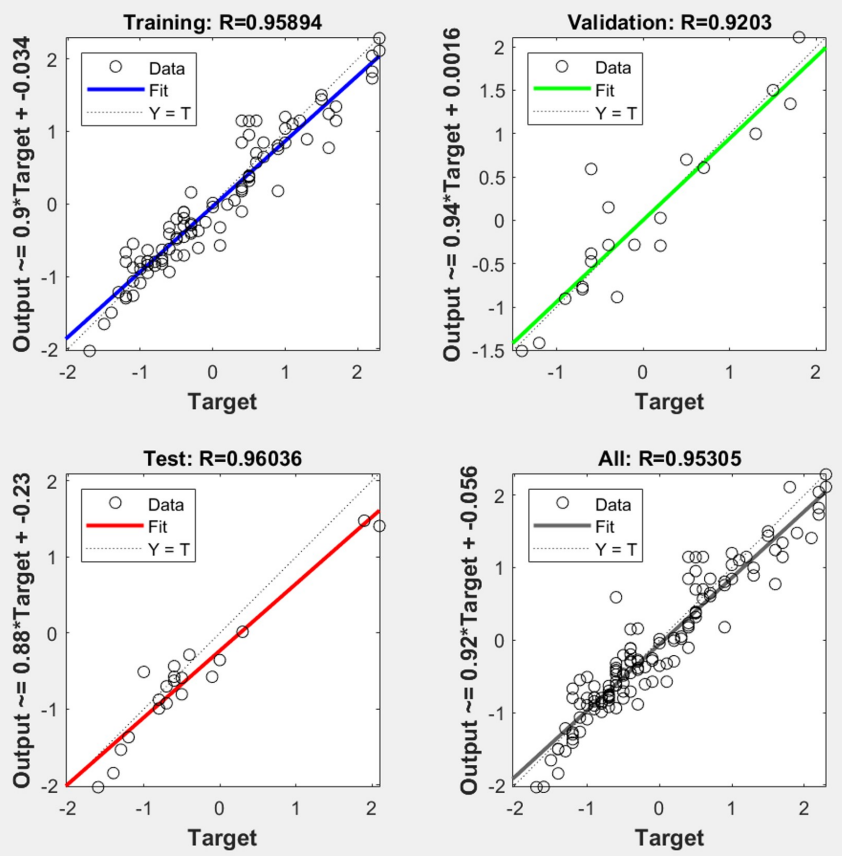

Figure 14. ANN results showing $R^{2}$ values.

the 28-day results. The reason may be that the RMSE of ANFIS model-1 is lower than that of ANFIS model-2. This condition arises because the dataset used to train the latter is built using the former model. Hence, the error accumulates while moving from ANFIS model-1 to ANFIS model-2, and this could be prevented if a dataset having both 3- and 28-day strengths for the same parameters is readily available. The error in ANFIS model- 2 does not contribute to the demerits of the model. The advantage of ANFIS model-2 is that it predicts the 28-day strength based on the 3-day strength, saving 25 days of curing time, which significantly contributes to decision-making. The ANFIS model results were verified using experimental results, and the measured results were found to be in good agreement with the predicted results, with a maximum deviation of $18 \%$, which seems to be unacceptable. However, the proposed model was based on the data by Yeh [21], and the reason for the

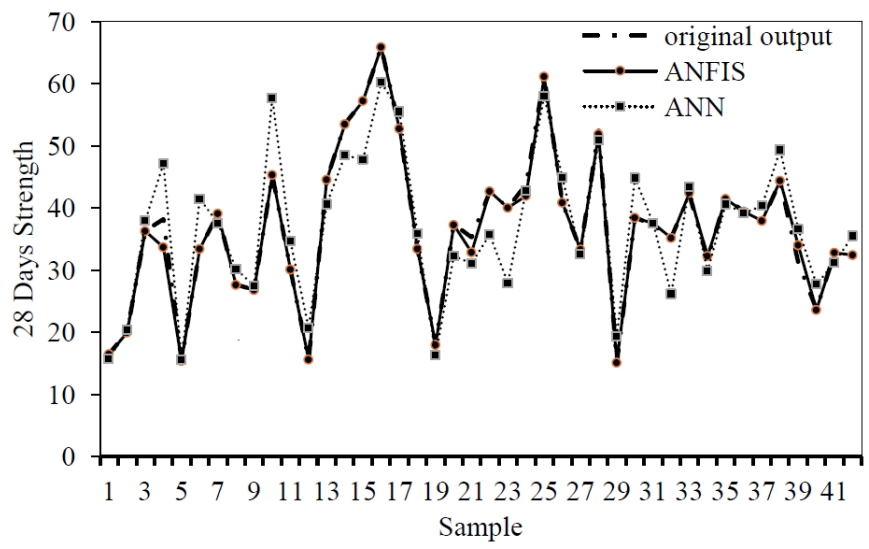

Figure 15. Comparison of ANFIS and ANN (present study) with original output (Yeh [21]).

deviation of $18 \%$ may be the fact that the material considered by Yeh [21] is from another continent. In addition, the authors considered only cement, FAs, CAs, and water/cement ratio, excluding the superplasticizer (which improves the strength as well as the filling ability); hence, this deviation may be acceptable.

\section{Comparison of Original, ANN, and ANFIS Results}

The ANFIS model results are compared with the ANN model and original outputs of Yeh [21], as shown in Figure 15. It is observed that the ANFIS model is much more accurate than the ANN model. The trend of the ANFIS results overlaps with the original compressive strength and proves to be superior to that of the ANN results. It is concluded that the ANFIS model results closely match the original results. In addition, there are significant deviations between the ANN model results and original results; however, the ANN model also follows the trend of the original results. 


\section{Conclusion}

The present study focused on developing a model for predicting the compressive strength of concrete using the ANFIS in MATLAB. The results predicted using ANFIS and ANN models were compared with the original results. Furthermore, experiments were conducted on selective mixes to verify the compressive strength obtained from the ANFIS model, and the following conclusions were drawn:

- The average percentage of error for the 3-day compressive strength is $6.33 \%$, whereas the same for the 28-day compressive strength is $17.07 \%$. The calculated error for the 3-day compressive strength is much smaller than that of the 28-day results. The reason may be that the RMSE of ANFIS model-1 is lower than that of ANFIS model2. The error in ANFIS model-2 does not contribute to the demerits of the model. The advantage of ANFIS model-2 is that it predicts the 28-day strength based on the 3-day strength, saving 25 days of curing time, which significantly contributes to decision-making.

- The training, checking, and validation errors for ANFIS model-2 are 1.119, 6.512, and 6.469 MPa, respectively. These are within the tolerance limit of the mix design in accordance with the Indian codal recommendations.

- The ANFIS model results are verified with the experimental results, and the measured results are found to be in good agreement with the predicted results, with a maximum deviation of $18 \%$. Although the deviation of $18 \%$ is seems unacceptable, the proposed model is based on the data by Yeh [21], who considered material from another continent.

- It is observed that the ANFIS model results closely match the original results. Moreover, there are significant deviations between the ANN model and original results; however, the ANN model also follows the trend of the original results.

\section{References}

[1] A. Kabir, M. Hasan, and K. Miah, "Predicting 28 days compressive strength of concrete from 7 days test result," in Proceedings of the International Conference on Advances in Design and Construction of Structures, Bangalore, India, 2012, pp. 18-22.
[2] J. D. Supe and M. K. Gupta, "Predictive model of compressive strength for concrete in-situ," International Journal of Structural and Civil Engineering Research, vol. 3, no. 1, pp. 90-102, 2014.

[3] M. Viviani, B. Glisic, K. L. Scrivener, and I. F. C. Smith, "Equivalency points: predicting concrete compressive strength evolution in three days," Cement and Concrete Research, vol. 38, no. 8-9, pp. 1070-1078, 2008.

[4] M. Akram, I. A. Rahman, and I. Memon, "A review on expert system and its applications in civil engineering,' International Journal of Civil Engineering and Built Environment, vol. 1, no. 1, pp. 24-29, 2014.

[5] A. Abraham, "Artificial neural networks," in Handbook of Measuring System Design. Hoboken, NJ: John Wiley \& Sons, 2005. https://doi.org/10.1002/0471497398.mm421

[6] P. Chopra, R. K. Sharma, M. Kumar, and T. Chopra, "Comparison of machine learning techniques for the prediction of compressive strength of concrete," Advances in Civil Engineering, vol. 2018, article no. 5481705, 2018. https://doi.org/10.1155/2018/5481705

[7] C. H. Chen, Fuzzy Logic and Neural Network Handbook. New York, NY: McGraw-Hill, 1996.

[8] P. Singhala, D. Shah, and B. Patel, "Temperature control using fuzzy logic," International Journal of Instrumentation and Control Systems, vol. 4, no. 1, pp. 1-10, 2014. https://doi.org/10.5121/ijics.2014.4101

[9] J. S. Jang, “ANFIS: adaptive-network-based fuzzy inference system," IEEE Transactions on Systems, Man, and Cybernetics, vol. 23, no. 3, pp. 665-685, 1993. https://doi.org/10.1109/21.256541

[10] M. C. Nataraja, M. A. Jayaram, and C. N. Ravikumar, "A fuzzy-neuro model for normal concrete mix design," Engineering Letters, vol. 13, no. 2, pp. 98-107, 2006.

[11] Bureau of Indian Standards, IS 10262: Guidelines for concrete mix design proportioning, 2009. https://archive org/details/gov.in.is.10262.2009.

[12] M. Neshat, A. Adeli, G. Sepidnam, and M. Sargolzaei, "Predication of concrete mix design using adaptive neural fuzzy inference systems and fuzzy inference systems," The International Journal of Advanced Manufacturing Technology, vol. 63, pp. 373-390, 2012. https://doi.org/10. 1007/s00170-012-3914-9 
[13] P. Ghoddousi, A. A. S. Javid, and J. Sobhani, "A fuzzy system methodology for concrete mixture design considering maximum packing density and minimum cement content," Arabian Journal for Science and Engineering, vol. 40, no. 8, pp. 2239-2249, 2015. https://doi.org/10.1007/s13369015-1731-9

[14] D. K. Sinha, S. Rupali, and S. Bawa, "Application of adaptive neuro-fuzzy inference system for the prediction of early age strength of high performance concrete," in Proceedings of 2019 International Conference on Data Science and Engineering (ICDSE), Patna, India, 2019, pp. 1-5. https://doi.org/10.1109/ICDSE47409.2019.8971798

[15] E. K. Vahidi, M. M. Malekabadi, A. Rezaei, M. M. Roshani, and G. H. Roshani, "Modelling of mechanical properties of roller compacted concrete containing RHA using ANFIS," Computers and Concrete, vol. 19, no. 4, pp. 435-442, 2017. https://doi.org/10.12989/cac.2017.19. 4.435

[16] A. Toghroli, E. Darvishmoghaddam, Y. Zandi, M. Parvan, M. Safa, M. M. Abdullahi, A. Heydari, K. Wakil, S. A. M. Gebreel, and M. Khorami, "Evaluation of the parameters affecting the Schmidt rebound hammer reading using ANFIS method," Computers and Concrete, vol. 21, no. 5, pp. 525-530, 2018. http://doi.org/10.12989/cac.2018.21.5.525

[17] H. E. Komleh and A. A. Maghsoudi, "Prediction of curvature ductility factor for FRP strengthened RHSC beams using ANFIS and regression models," Computers and Concrete, vol. 16, no. 3, pp. 399-414, 2015. https://doi.org/10.12989/cac.2015.16.3.399

[18] M. Mohammadhassani, H. Nezamabadi-pour, M. Jameel, and K. Garmasiri, "Applications of the ANFIS and LR in the prediction of strain in tie section of concrete deep beams," Computers and Concrete, vol. 12, no. 3, pp. 243259, 2013. https://doi.org/10.12989/cac.2013.12.3.243

[19] Parveen and D. Singhal, "Development of mix design method for geopolymer concrete," Advances in Concrete Construction, vol. 5, no. 4, pp. 377-390, 2017. https://doi. org/10.12989/acc.2017.5.4.377

[20] MathWorks, "MATLAB - Statistics Toolbox Release 2018a," 2021, Available: https://www.mathworks.com/ products/statistics.html

[21] I. C. Yeh, "Modeling of strength of high-performance concrete using artificial neural networks," Cement and
Concrete Research, vol. 28, no. 12, pp. 1797-1808, 1998. https://doi.org/10.1016/S0008-8846(98)00165-3

[22] Bureau of Indian Standards, IS 456: Plain and reinforced concrete - Code of practice, 2000. https://archive.org/ details/gov.in.is.456.2000

[23] H. S. Chore and R. B. Magar, "Prediction of unconfined compressive and Brazilian tensile strength of fiber reinforced cement stabilized fly ash mixes using multiple linear regression and artificial neural network," Advances in Computational Design, vol. 2, no. 3, pp. 225-240, 2017.

[24] A. Kumar and S. Rupali, "Prediction of UCS and STS of Kaolin clay stabilized with supplementary cementitious material using ANN and MLR," Advances in Computational Design, vol. 5, no. 2, pp. 195-207, 2020. https://doi.org/10.12989/acd.2020.5.2.195

[25] M. I. Lourakis, "A brief description of the LevenbergMarquardt algorithm implemented by levmar," Foundation of Research and Technology, vol. 4, no. 1, pp. 1-6, 2005.

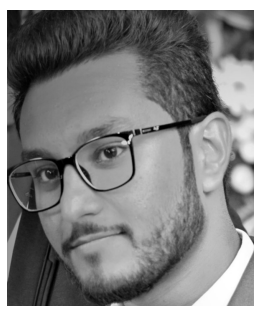

Deepak Kumar Sinha received M.Tech in Structural and Construction Engineering from Dr. B.R. Ambedkar National Institute of Technology Jalandhar in 2019. His research interests include fuzzy logic, ANFIS, mix design of concrete, high performance concrete.

E-mail: deepaksinha.official@gmail.com

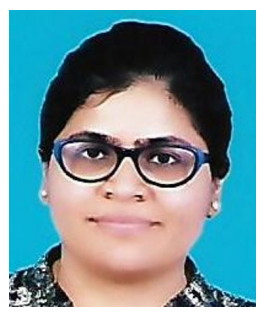

Rupali Satavalekar is an Assistant Professor, Dr. B R Ambedkar National Institute of Technology Jalandhar. E-mail: satavalekarr@nitj.ac.in

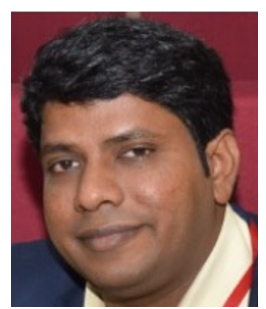

Senthil Kasilingam is an Assistant Professor, NIT Jalandhar. E-mail: kasilingams@nitj.ac.in 